Nogueira, E.M.N.; Ferko, G.P.S.; Costa-Neto, C.P.L.; Falcão, M.T.; Rodrigues, R.M. Etnoturismo e etnoecologia: possibilidades para o desenvolvimento sustentável em comunidades indígenas. Anais do IX Congresso Nacional de Ecoturismo e do V Encontro Interdisciplinar de Turismo em Unidades de Conservação. Revista Brasileira de Ecoturismo, São Paulo, v.6, n.4, nov-2013, pp.121-140.

\title{
Etnoturismo e etnoecologia: possibilidades para o desenvolvimento sustentável em comunidades indígenas
}

\section{Ethnic tourism and ethnoecology: possibilities for a sustainable development at the indigenous communities}

\section{Elizabete Melo Nogueira, Georgia Patrícia da Silva Ferko, Canrobert Penn Lopes Costa Neto, Márcia Teixeira Falcão, Raimunda Maria Rodrigues}

\section{RESUMO}

Este trabalho tem o objetivo de discutir e refletir sobre a prática do etnoturismo em comunidades indígenas sob a perspectiva do desenvolvimento sustentável, considerando as contradições, interseções e relações entre os dois temas. Buscou-se além de uma discussão teórica, mergulhar em um caso prático para entender como o etnoturismo pode ser utilizado de maneira sustentável na Terra indígena Raposa Serra do Sol (TIRSS), região Ingarikó, a partir do mapeamento das relações entre usos e conhecimentos dos indígenas desta região, utilizando a etnoecologia. A pesquisa tem caráter qualitativo, descritivo e exploratório. Identificou-se que o ecoturismo embora ressalte a preservação do ambiente é ao mesmo tempo nocivo aos recursos naturais quando não planejado. As comunidades indígenas pesquisadas acreditam que a inclusão dessa atividade produtiva promoveria mudanças para a população, considerada marginalizada, pois esta passaria a ter acesso a mecanismos de produção, sejam eles materiais ou de caráter social e cultural. Neste sentido, o ecoturismo poder ser um caminho para o desenvolvimento sustentável associando-se à etnoecologia. Para tanto, faz-se necessário um planejamento visando à identificação das estratégias mais adequadas para cada comunidade, conforme desenvolvimento local almejado.

PALAVRAS-CHAVE: Terra Indígena Raposa Serra do Sol; Desenvolvimento Sustentável; Etnoturismo; etnoecologia.

\section{ABSTRACT}

Ethno tourism and ethno ecology: possibilities for a sustainable development at the indigenous communities This study aims to discuss and reflect on the practice of ethno tourism in indigenous communities from the sustainable development perspective, considering that there are contradictions and intersections relations between the two issues. Beyond a theoretical discussion, it was sought to dive into a case study to understand how ethno tourism can be used in a sustainably way on Indigenous Land Raposa Serra do Sol (TIRSS) Ingarikó region from the mapping of relations of uses, this knowledge of indigenous region using ethnoecology. The research is qualitative, descriptive and exploratory. Perharps was identified that although ecotourism emphasizes the environment preservation, when not planned is harmful to natural resources. The indigenous communities surveyed believe that the inclusion of this productive activity should promote changes in people that are considered marginalized, they would have access to the mechanisms of production, whether material or social and cultural. In this way, ecotourism can be a path for sustainable development by joining ethnoecology, therefore it is necessary a planning, to identify which strategies would be most appropriate for a community that configure a desired local development.

KEYWORDS: Indigenous Land Raposa Serra do Sol; Sustainable Development; Etno Tourism; Ethno Ecology. 


\section{Introdução}

As questões relacionadas ao desenvolvimento sustentável e ecoturismo, de maneira geral, têm sido foco de diversos estudos e pesquisas no âmbito acadêmico, haja vista que existe uma preocupação relacionada à interação do homem com o meio ambiente e os impactos resultantes dessa relação. Nesse sentido, este trabalho tem o objetivo de discutir e refletir sofre a prática do ecoturismo em comunidades indígenas sob a perspectiva do desenvolvimento sustentável, considerando as contradições e interseções entre os dois temas.

Entende-se que o turismo consiste no somatório das ações e relações que surgem da inter-relação de turistas, provedores de negócios, governos e comunidades anfitriãs no processo de atrair e hospedar visitantes. Isto leva a assinalar que o turismo é uma combinação de atividades e serviços, que pode proporcionar experiências e também satisfação aos visitantes e receptores.

Acrescenta-se que a atividade turística promove o contato entre pessoas que trocam conhecimentos culturais; fomenta mudanças socioeconômicas e ambientais na comunidade receptora. Ruschmann (2008, p.34) afirma que "os impactos do turismo referem-se a gama de modificações ou sequência de eventos, provocados pelo processo de desenvolvimento turístico nas localidades receptoras".

Por essa linha de pensamento, entende-se que qualquer forma de turismo gera impactos, como resultado das relações mantidas, antes, durante e depois da estada dos visitantes, cuja intensidade pode ser minimizada por fatores espaciais e temporais restritos.

Em função dos efeitos negativos, o desenvolvimento do turismo é "assunto proibido" em determinadas regiões, como exemplo algumas regiões indígenas, o que promove o isolamento dessas populações. Há uma dificuldade de entendimento sobre os efeitos positivos dessa atividade, tais como a melhoria da qualidade de vida da comunidade local (criação de infraestrutura, saúde, educação, moradia entre outras coisas), além do conhecimento advindo das experiências compartilhadas pelos visitantes (cultura e modos de vida diferente).

Sobre o turismo em áreas indígenas, Chernela (2004, p.216) ressalta ser "imperativo que se criem maneiras viáveis para que continuem a preservar suas terras, melhorando simultaneamente a educação, a saúde e o seu padrão de vida" local. Ressalta-se que os povos indígenas têm pela terra um sentimento maternal e alguns lugares são considerados sagrados, inviabilizando a visitação. Nessa perspectiva, o ecoturismo seria uma alternativa interessante, podendo se firmar como uma proposta de turismo de massa, no qual predomina o consumo desmedido do patrimônio cultural das comunidades locais.

Como observa Faria (2012, p.61), esse tipo de turismo utiliza o patrimônio cultural, natural e a "propriedade coletiva" dos povos indígenas, por isso deveria assegurar-lhes "participação no processo de gestão e no recebimento de royatlties", uma vez que o turista desfruta do convívio, assiste às danças e às cerimônias religiosas, dentre outros ritos dos povos indígenas.

De acordo com Neiman e Mendonça (2005, p18), "o ecoturismo é hoje uma ati- 
vidade que funciona como instrumento de aproximação entre o ser humano e o meio ambiente selvagem, principalmente em Unidades de Conservação", promovendo o contato dos visitantes com o ambiente natural e a cultura local. Contato este capaz de contribuir para o aprendizado dos turistas e anfitriões e promover consciência ambientalista.

Pelegrini Filho (2000, apud BRITO 2009, p.27) afirma que o etnoturismo ou turismo "em áreas indígenas" dialoga com o conceito de cultura e configura-se como "turismo alternativo", por possuir um público mais seleto e conter o turismo de massa. O turismo alternativo é apontado por Mieczkowski (1995) como um conjunto de atividades opostas ao turismo de massa, com formas não associadas ao turismo convencional de larga escala.

Para Azevedo (2007), os elementos que fazem parte do etnoturismo são o ecoturismo, sustentabilidade, natureza e cultura, e estes se interrelacionam de maneira singular. Neste segmento, pode-se também utilizar a etnoecologia, que, segundo Toledo (1992) e Nazarea (1999), é o estudo dos conhecimentos, estratégias, atitudes e ferramentas que permitem às diferentes culturas produzirem e reproduzirem as condições materiais de sua existência social, por meio de um manejo apropriado dos recursos naturais.

Marques (2005, p.108) aponta que "os visitantes que praticam o turismo alternativo" não se contentam somente em conhecer os espaços turísticos, pois estão dispostos a ampliar seus conhecimentos sobre os atrativos, aprender a sua história, contribuir para conservação e conviver com a comunidade local.

Com a etnoecologia é possível aprofundar o conhecimento sobre o modo de vida diferenciado dos indígenas, compreendendo as diferentes dimensões e aspectos das relações entre os povos indígenas e o ambiente natural. Muitos estudiosos, e até mesmo curiosos, passaram a se interessar pelas culturas locais e populações tradicionais, através do estudo de seus saberes e usos do ambiente natural. Seja para fins profissionais ou pela busca do exótico, cada vez mais as comunidades indígenas são procuradas por turistas.

Neste trabalho, buscou-se, além de uma discussão teórica, mergulhar em um caso prático para entender como o etnoturismo pode ser utilizado de maneira sustentável na TIRSS, região Ingarikó, a partir do mapeamento das relações de usos e conhecimentos dos indígenas dessa região, utilizando a etnoecologia. Trata-se de uma pesquisa-participante do tipo descritiva, qualitativa e exploratória. A coleta de dados foi dividida em três etapas. Na primeira fase, realizou-se a pesquisa bibliográfica, buscando obter embasamento teórico para posterior discussão dos dados coletados na pesquisa de campo. Esta ocorreu com a imersão dos pesquisadores na área delimitada, momento em que participaram de reuniões e assembleias. Na terceira fase, procedeu-se a aplicação de entrevistas para apreender a percepção dos indígenas sobre o turismo e o desenvolvimento sustentável.

Cabe mencionar que a demanda por áreas naturais, a fim de um descanso em contato com a natureza, e por áreas preservadas, confirmam o potencial do etnoturis- 
mo no Estado de Roraima, especialmente na Serra do Sol, onde essa atividade pode ser diversificada. Conforme propõem Wearing e Neil (2001), essa área é propicia para atividades que envolvem desde a "observação de pássaros, estudo científico, safáris fotográficos, trekking, mergulho, canoagem, caminhada na mata", trilhas interpretativas, até o convívio com as comunidades.

Este artigo está estruturado da seguinte forma: introdução, marco teórico de desenvolvimento sustentável, ecoturismo, e ecologia, considerados conceitos-chave para a análise de resultados e discussões.

\section{Ecoturismo e o etnoturismo}

O século $X X$ foi marcado pelo crescimento da procura pelo ecoturismo e por significativas mudanças nas viagens para áreas naturais. De acordo com a Organização Mundial do Turismo - OMT (2002), o ecoturismo é um segmento que tem crescido mundialmente em torno de aproximadamente $20 \%$, ao passo que o turismo convencional cresce 7,5\%. O mesmo órgão ressalta que o Ecoturismo, nos últimos 15 anos, recebeu $90 \%$ a mais de investimentos. Segundo o World Travel \& Tourism Council WTTC (2012), a contribuição do setor para a economia global em 2011 foi de 6,3 biIhões do PIB, 255 milhões de postos de trabalho, 743 milhões de dólares em investimentos e 1,2 bilhões de dólares em exportações. Isso representa uma contribuição de 9\% do Produto Interno Bruto (PIB), sendo 5\% de investimentos e 5\% de exportações e 1 em cada 12 postos de trabalho.

De acordo com Campos (2005, p.3), "o ecoturismo é uma nova concepção de turismo que supera as práticas convencionais". Segundo o autor, esta modalidade de turismo é nova, pois apresenta características de conservação do meio ambiente e de cunho educacional, na medida em que o turista tem respeito pelo espaço visitado.

Faria (2012, p.57) define ecoturismo como:

O turismo planejado que promove a interação entre natureza e comunidade com vistas a uma utilização sustentável e conservacionista do patrimônio natural e cultural, proporcionando melhoria na qualidade de vida da população envolvida sem causar impactos negativos à sua territorialidade.

Para Nogueira e Ghedin (2010, p.784), "definir o ecoturismo passa a ser um exercício que exige práticas diferentes dos vários atores sociais inseridos no mesmo contexto". De maneira geral, o ecoturismo surge como uma forma de valorizar e conservar as atividades tradicionais das comunidades locais.

Como afirma Chernela (2004, p.215), o foco do ecoturismo é a valorização dos recursos e o fornecimento de receitas para "os povos locais" que contribuem para a proteção dos "ecossistemas ameaçados", para a conservação da biodiversidade, por meio de uma "aliança entre os defensores ambientais, a comunidade internacional de desenvolvimento e as populações locais".

Dale (2005, p.8) afirma que uma das grandes riquezas do ecoturismo consiste na gente que o promove, que o executa, que o planeja, visto que, apesar da rentabili- 
Nogueira, E.M.N.; Ferko, G.P.S.; Costa-Neto, C.P.L.; Falcão, M.T.; Rodrigues, R.M.

dade econômica do turismo, quando se pensa nele em termos de ambiente natural, tem-se como proposta o bem-estar das comunidades locais.

A atividade de ecoturismo praticada em áreas naturais pode contribuir para a conservação da área de destino e para manutenção dos valores da comunidade local. Na medida em que a filosofia do ecoturismo é o desenvolvimento sustentável, considerando tanto a diversidade biológica quanto a qualidade de vida das populações visitadas (NOGUEIRA; GHEDIN 2010, p.784).

Posto que nos atrativos ecoturísticos esteja envolvido o patrimônio natural e cultural, nesse contexto submerge o turismo cultural que, segundo os marcos conceituais do Ministério do Turismo - MTur (2010, p.15), "compreende as atividades turísticas relacionadas à vivência do conjunto de elementos significativos do patrimônio histórico e cultural e dos eventos culturais, valorizando e promovendo os bens materiais e imateriais da cultura". Nesse sentido, entende-se que uma das modalidades de turismo cultural é o etnoturismo.

O etnoturismo é um segmento relativamente novo e as definições acerca do tema se confundem, uma vez que ecoturismo, sustentabilidade e turismo cultural são atividades inseridas dentro das práticas de turismo que acontecem em áreas ou comunidades indígenas. Independente da confusão dos termos, essa atividade consiste no aproveitamento da cultura de uma determinada etnia, de modo que todas as manifestações culturais de um povo passam a ser um atrativo para os visitantes. E, certamente, tais atividades corresponderão aos preceitos do ecoturismo, turismo sustentável, turismo de natureza e de turismo cultural.

A principal ideia do etnoturismo é aproveitar o potencial turístico e divulgar a importância e a necessidade de conservação do ambiente, tanto em relação ao patrimônio natural quanto ao cultural e tradicional. De acordo com Faria (2012, p.58), "etnoturismo é um tipo de turismo cultural que utiliza como atrativo a identidade, a cultura de um determinado grupo étnico (japoneses, alemães, ciganos, indígenas etc.)".

O turismo étnico é inspirado na diversidade étnica dos povos com suas identidades específicas, sendo desenvolvido não exclusivamente por eles, ou seja, ainda ocorre a representação dessas identidades étnicas por outros grupos da sociedade nacional, fato que justificaria, em parte, o caráter comercial da atividade (FARIA, 2012, p. 60).

De acordo com a OMT (2002, p.168), o turismo étnico "é voltado para as tradições e estilo de vida de um grupo e utilizado, principalmente, para destacar o turismo nas comunidades ou enclaves específicos, em processo de desenvolvimento". Ainda de acordo com a OMT, o turista procura a etnicidade como motivação para as viagens, muitas vezes para observar e/ou vivenciar experiências únicas sobre a organização social e o estilo de vida das populações visitadas.

Chambers (2000, p.100), ao referir-se ao turismo étnico, afirma que a termino- 
logia "tem sido usada para referir as atividades que envolvem turistas na experiência de eventos culturais e situações que são distintas das suas próprias". Nessa perspectiva, nesse tipo de turismo, muitos grupos minoritários têm aproveitado tal atividade para fortalecer sua identidade, diferenciando-se do estereótipo nacional. Usando as palavras de Chambers (Ibdem), "existem ocasiões em que as minorias étnicas têm manejado o uso do turismo para afirmar sua própria identidade e diferenciar-se da imagem nacional".

Para o Mtur (2010, p.11), no turismo étnico, deve-se considerar que:

o turista busca estabelecer um contato próximo com a comunidade anfitriã, participar de suas atividades tradicionais, observar e aprender sobre suas expressões culturais, estilos de vida e costumes singulares. Muitas vezes, essas atividades articulam-se com uma busca pelas próprias origens do turista, em um retorno às tradições de seus antepassados.

Corroborando com essa ideia, Leal (2009, p.246) afirma que "o turismo étnico é alimentado pelo interesse dos visitantes em ter acesso à cultura e ao povo indígena, buscando conhecer seus costumes e crenças no próprio ambiente de vivência dos mesmos".

Para que o etnoturismo seja sustentável em nível ecológico e cultural, é importante que a comunidade informe aos visitantes os costumes locais, as possibilidades de contato, celebrações religiosas, hábitos e expectativas da população quanto ao processo de visitação, inclusive sobre possíveis problemas a serem gerados na relação entre moradores e visitantes. Nesse sentido, é imperioso que a população local reconheça e valorize a identidade étnica, incluindo suas línguas, tradições organizacionais, técnicas de produção, ocupação da terra e recursos naturais, na perspectiva de um convívio pacífico através do intercâmbio cultural que o etnoturismo é capaz de propiciar.

Não se pode deixar de mencionar que o etnoturismo, assim como outras atividades, deve caminhar segundo as bases legais, a fim de facilitar a fiscalização, garantir a preservação dos povos, suas culturas e tradições, além de resguardar o meio ambiente, visando sempre ao desenvolvimento sustentável.

\section{Relação entre etnoecologia e desenvolvimento sustentável nas culturas indígenas}

A expressão desenvolvimento sustentável foi utilizada publicamente em 1979, durante o Simpósio das Nações Unidas cujo tema debruçava-se sobre a inter-relação entre recursos, ambiente e desenvolvimento. Contudo, somente em 1987, quando Gro Harle Brundtland, primeira ministra da Noruega, apresentou o relatório "Nosso Futuro Comum", também conhecido como "Relatório Brundtland", apareceu pela primeira vez de forma clara o conceito de "Desenvolvimento Sustentável", que é "o atendimento das necessidades do presente sem comprometer a possibilidade de as gerações futuras atenderem as suas próprias necessidades" (WCED, 1991).

Esse acontecimento foi anterior à Rio-92, evento cujo objetivo foi buscar meios que permitissem o desenvolvimento socioeconômico e a conservação da natureza, "onde o meio ambiente e o desenvolvimento são duas faces de uma mesma moeda" (SACHS, 1993, p.30). A partir da Rio-92, Maurice Strong (1991), secretário geral da 
Conferência das Nações Unidas para o Meio Ambiente e Desenvolvimento (CNUMAD), empregou os conceitos de "Ecodesenvolvimento" e "Desenvolvimento Sustentável" como sinônimos e apontou cinco dimensões para se planejar o desenvolvimento, a saber: sustentabilidade social; sustentabilidade econômica; sustentabilidade ecológica; sustentabilidade espacial e de sistemas agrícolas integrados. Dimensões essas que devem respeitar a cultura, a identidade e tradições das comunidades locais (SACHS, 1993).

Desde então, surgiram diferentes estudos que discutem o conceito de desenvolvimento sustentável. Independente da área, há o consenso de que consiste em uma situação de melhoria na qualidade de vida dos cidadãos - do presente e do futuro - com um nível de uso dos ecossistemas que não exceda sua capacidade regenerativa e assimiladora dos rejeitos do ambiente natural (FERNANDEZ, 2011, p.117).

O desenvolvimento sustentável não pode ser entendido como um estado fixo e harmônico. Mas sim como um processo de mudanças em que alterações na utilização dos recursos e gestão dos investimentos orientam o desenvolvimento para ações coerentes com as necessidades futuras e presentes, exigindo das pessoas formas alternativas de pensar e entender a natureza antes de escolher as técnicas de produção. Para Daly (2004, p.198), desenvolver-se "significa expandir ou ter consciência de seu potencial para, gradualmente, atingir um estado mais abrangente, maior, ou melhor".

Deve-se considerar que pensar em mudanças sociais é ter a compreensão dos três pilares do desenvolvimento sustentável: o econômico, que leva em consideração a ideia de capital econômico; capital humano e intelectual; e o social que deve equalizar o sistema social, ambiental e econômico de modo a progredir de maneira desejada e o ambiental, cujos benefícios por ele gerados podem ser comercializados.

Dessa maneira, o desenvolvimento sustentável tem como propósito, segundo Silva (2012, p.2), "mudanças fundamentais no sistema de governança de alimentos e agricultura e uma partilha equitativa dos custos de transição e benefícios", associados a projetos que utilizem recursos naturais e estabeleçam critérios de regularização fundiária para aqueles que não possuem títulos de terra. Afinal, não se pode admitir que indígenas, ribeirinhos e colonos, moradores de ecossistemas riquíssimos, sejam miseráveis e dependam unicamente de políticas assistencialistas. "É também inadmissível que essas populações sejam forçadas a desmatar, na busca de melhorar o seu bem estar" (VIANA, 2004, p.2).

Dessa maneira, o desenvolvimento sustentável centrado na administração dos recursos naturais e da produção, por ser regulada pelo poder público, deve garantir a sustentabilidade na expectativa do bem comum. Por essa linha de pensamento, fica manifesto que o desenvolvimento sustentável está orientado sob a ótica efetiva das potencialidades sociais, culturais e econômicas da sociedade.

Conforme afirmam Costabeber e Caporal (2003, p.158), "o desenvolvimento sustentável implica, ademais, uma transformação progressiva da economia e da sociedade, aumentando o potencial produtivo e assegurando a igualdade de oportunidades para todos", na perspectiva de atender às necessidades de cada sociedade, sendo fundamental a valorização do conhecimento tradicional pelo conhecimento científico, uma vez que este poderá considerar que as seis dimensões da sustentabilidade são reconhecidas como 
importantes indicadores de monitoramento de sustentabilidade.

Essa autonomia, sob o ponto de vista cultural, incide na utilização e inserção de práticas produtivas que garantem o abastecimento das suas necessidades básicas, bem como permitem a produção de excedentes a serem utilizados na geração de renda. A elaboração dessas práticas baseia-se em conhecimentos da etnoecologia, já que as relações ecológicas existentes, tomadas no seu conjunto, mostram os caminhos da sustentabilidade ambiental.

Frente a essas possibilidades de serviço, o ecoturismo pode ser um exemplo de turismo sustentável, na medida em que todos os envolvidos no processo possam obter resultados positivos, o turista tendo suas experiências e a comunidade mantendo viva para as futuras gerações sua cultura, suas tradições e sua história, além dos benefícios econômicos.

Ruschmann (2008) afirma que o turismo sustentável e o desenvolvimento sustentável estão intimamente ligados à sustentabilidade do meio ambiente. Ambos dependem da viabilidade de recursos de base e sua consequente preservação. Uma das grandes inquietações nesse processo é o equilíbrio entre os interesses econômicos que o turismo estimula e o desenvolvimento da atividade que preserve o meio ambiente. Em se tratando de áreas indígenas, o alcance desse equilíbrio não é tarefa fácil porque seu controle depende de critérios preconizados e valores subjetivos.

É interessante frisar que o desenvolvimento sustentável do turismo requer a gestão dos recursos (tempo, pessoas, tecnologias) sobre os quais muitas vezes as comunidades receptoras não detêm conhecimento, transferindo essa responsabilidade ou sendo obrigadas a entregá-la a outros grupos, geralmente empresas organizadas. Mas, por causa dessa dificuldade, não se deve retirar a possibilidade do ecoturismo em áreas indígenas.

Alguns aspectos relacionados aos conhecimentos científicos e indígenas são abordados por Littler (2002, p.41). Primeiro, a sofisticação e complexidade das ciências indígenas, que "como tal oferecem um novo universo para estudos em profundidade". Segundo o autor, "os povos indígenas que habitam as florestas tropicais" dispõem de conhecimento a respeito dos ecossistemas pouco "conhecidos pela ciência ocidental e ligados ao interesse mundial por parte dos ambientalistas". Terceiro, a possibilidade de desaparecimento dos conhecimentos ambientais indígenas, assim como "agravado pelas inúmeras invasões sofridas pelas sociedades indígenas, o que às vezes põe em questão sua própria sobrevivência como grupo".

A manutenção dos conhecimentos indígenas não está ligada apenas à classificação dos elementos da natureza, mas por meio de um processo de classificação criterioso, o qual obedece a determinadas dimensões.

[...] não existe uma classificação única dos elementos da natureza (plantas, animais, fungos, solo, água, rochas, vegetação) e seus sistemas rankings são feitos obedecendo vários critérios e categorias e têm múltiplos significados e dimensões, ou seja, são multicritérios e polissêmicos (TOLEDO; BARRERA-BASSOLS, 2008, p.110). 
De acordo com Nogueira (2013), na relação natureza e cultura são ampliados os limites dos diversos campos disciplinares, desde as ciências biológicas, com destaque para a Botânica, a Zoologia e a Ecologia, até as ciências sociais, com ênfase para a Antropologia e a Sociologia. As ciências biológicas tendem a destacar as questões relacionadas à etnobiologia; enquanto as ciências sociais procuram evidenciar o conflito nas relações humanas, na perspectiva de que as populações tradicionais vivam em perfeita harmonia com o ambiente natural e com a sociedade envolvente.

Trata-se de uma visão que considera tais populações como sendo frágeis e incapazes de se adaptar a novos contextos, implicando em uma visão estática de cultura, pautada na segregação ao invés da dinâmica cultural, na crença de que, manter essas populações em isolamento em relação à sociedade abrangente seria uma forma de conservar suas tradições e os ambientes onde vivem (SOUZA et al, 2009, p.10).

Essa visão das populações tradicionais coaduna-se com Diegues (2005, p. 37), quando afirma que tais populações, apesar de "iletradas", de viverem "geograficamente" distantes da sociedade envolvente e "sem poder político", vêm conservando por séculos seus usos e costumes, sendo responsáveis pela conservação do ambiente natural. Nesse aspecto, o desenvolvimento dos saberes pertence à coletividade e a educação é responsabilidade de todos.

A transmissão desse conhecimento se dá por meio da língua e, até onde sabemos, não lança mão da escrita; quer dizer, é um conhecimento ágrafo. A memória é então o recurso mais importante da vida desses povos. Sendo um conhecimento que se transmite no espaço e no tempo pela língua, configura-se e responde a uma lógica diferente: a da oralidade (TOLEDO; BARRERA-BASSOLS, 2009, p.35).

Nogueira (2013) afirma que a experiência dos mais velhos é transmitida pela oralidade de modo que a relação dos povos indígenas com o meio ambiente é descrita e interpretada pela própria comunidade. Toledo e Barrera-Bassols $(2008$, p.54) afirmam que, historicamente, os povos indígenas dominam a prática de uso dos recursos. Esse conhecimento sobre os recursos naturais são "transmitidos de geração para geração", por meio da oralidade, "daí que os textos são geralmente um conhecimento não escrito".

Nesse sentido, para Nogueira (2013), o saber tradicional sintetiza a relação dos povos indígenas com a natureza e o espaço e o tempo. Saber esse acumulado e transmitido em uma relação direta entre o aprendiz, seus pais e avós, de acordo com a capacidade de compreensão de cada indivíduo.

Segundo Toledo e Barrera-Bassols (2009, p.35), no "eixo espacial, os conhecimentos são revelados por um só indivíduo (informante)", que transfere seus conhecimentos para a comunidade à qual pertence. Na família, essa transmissão ocorre de "acordo com o gênero e idade", uma vez que "cada um de seus membros realiza atividades específicas que outorgam ao conhecimento sua própria particularidade". 
De acordo com Toledo e Barrera-Bassols (2009), o conhecimento temporal é repassado por um só informante e sintetizado em três vertentes, conforme descrito abaixo:

[...] (i) a experiência historicamente acumulada e transmitida por meio de gerações por uma cultura rural determinada; (ii) a experiência socialmente compartilhada pelos membros de uma mesma geração (ou um mesmo tempo generacional); e (iii) a experiência pessoal e particular do próprio produtor e sua família, adquirida pela repetição do ciclo produtivo (anual) paulatinamente enriquecido por variações, eventos imprevistos e surpresas diversas (TOLEDO; BARRERA-BASSOLS, 2009, p.35).

Para Nogueira (2013, p.31) "esse processo de transmissão de conhecimento mantém as lembranças, solidificando a memória do povo". É o que Toledo e BarreraBassols (2009, p.36) definem como "formidável mecanismo de memorização, quer dizer, de representação, formação e manutenção de lembranças, que no fundo expressa certo código de memória", sobre a natureza e a cultura.

[...] os saberes locais incorporam uma visão monista do mundo, portanto, a natureza e cultura são aspectos que não podem ser separados. Não obstante os saberes locais serem adquiridos por meio do processo de aprendizagem experimentada de maneira diferenciada de acordo com a idade e o sexo, o conhecimento coletivo total deve ser entendido como uma teoria social ou como uma epistemologia local sobre o mundo circundante (TOLEDO; BARRERA-BASSOLS, 2009, p.108).

Nesse sentido, segundo Muñoz (2003, p.294) "saber reconhecer as plantas úteis é resultado de uma disciplina de iniciação ao cuidado da terra e cultivo". Esse aprendizado tem como princípio a ideia de que as técnicas de conhecimento indígena envolvem a pessoa no seu meio natural, na vida vegetal e animal, em uma prática de respeito e apropriação dos recursos naturais, como parte de um processo evolutivo entre a natureza e a cultura. Corroborando com esse pensamento, Reyes-García e Sanz (2007, p.51) afirmam que "o conhecimento ecológico local" é organizado, apoiado nas "interações cotidianas" das populações tradicionais com ambiente natural e essas interações podem "contribuir para a concepção e produção de meios de vida sustentáveis".

Esse estudo do conhecimento e das conceituações vindas de comunidades tradicionais sob a percepção do mundo natural, visando a entender como a natureza influencia na construção das crenças e na adaptação do indivíduo em certos ambientes, é denominado de etnoecologia.

A etnoecologia das culturas tradicionais está ligada diretamente à etnociência que, segundo Diegues (2005, p.42), "é a parte da linguística que estuda o conhecimento das populações humanas sobre os processos naturais, tentando descobrir a lógica sobre o conhecimento humano do mundo natural, as taxonomias e classifica- 
Nogueira, E.M.N.; Ferko, G.P.S.; Costa-Neto, C.P.L.; Falcão, M.T.; Rodrigues, R.M.

ções totais".

Para Toledo (1992) e Nazarea (1999), a etnoecologia é o estudo dos conhecimentos, estratégias, atitudes e ferramentas que permitem às diferentes culturas produzir e reproduzir as condições materiais de sua existência social, por meio de um manejo apropriado dos recursos naturais. Enquanto Marques (2001) define a etnoecologia como:

[...] campo de pesquisa (científica) transdisciplinar que estuda os pensamentos (conhecimentos e crenças), sentimentos e comportamentos que intermedia as interações entre as populações humanas que os possuem e os demais elementos dos ecossistemas que as incluem, bem como os impactos daí decorrentes. (Marques, 2001, p.37).

Nogueira (2013, p.32) explica que o conhecimento local é preservado à medida que se analisa como as comunidades lidam com o manejo, a sustentabilidade, a conservação e os saberes tradicionais. Os saberes das culturas tradicionais passam a ser valorizados pelas ciências como forma de aproximar o conhecimento científico do conhecimento dos locais, partindo das inter-relações, envolvendo humanos em seus ambientes, descobrindo técnicas e práticas, sem tentar "reconhecer nos outros disciplinas que só existem entre nós da academia" (CAMPOS, 2002, p.83).

É pela etnoecologia que Bassi, Souza e Kubo (2010, p.7) destacam a "importância da atenção aos saberes relacionados à natureza em suas dimensões práticas e simbólicas, por intermédio dos estudos da ciência de um povo". Ciência essa em que a diversidade cultural, biológica, econômica e técnicas de produção são valorizadas pelos pesquisadores. Assim:

Tanto a etnoecologia como a educação ambiental estão envolvidas com a conservação da diversidade de grupos culturais e, por extensão, da diversidade biológica, por meio da compreensão, valorização e difusão dos conhecimentos e práticas tradicionais. Especificamente a educação ambiental, deve suscitar nas comunidades tradicionais, a reflexão sobre o fortalecimento de seus costumes culturais (NORDI et al., 2001, p.136).

A etnoecologia aborda a relação das comunidades com o ambiente natural, destacando o uso dos recursos naturais, as práticas de manejo, considerando as características ecológicas das espécies e dos ecossistemas. Essa abordagem engloba a valorização e compreensão da diversidade biocultural, fazendo a conexão entre o conhecimento ecológico tradicional e o conhecimento ecológico científico, uma vez que o conhecimento prático dos locais sobre o ambiente natural, taxonomia, hábitos alimentares e produção são fonte de informações para subsidiar a conservação e utilização dos recursos naturais de forma sustentável.

É como alude Hanazaki (2006, apud NAZAREA,1999, p.2): 
[...] a etnoecologia investiga os sistemas de percepção, cognição e uso do ambiente natural, mas também não pode mais ignorar os aspectos históricos e políticos que influenciam uma dada cultura, bem como as questões relacionadas à distribuição, acesso e poder que dão forma aos sistemas de conhecimento e nas práticas deles resultantes.

De acordo com Nogueira (2013), é inegável que nos dias atuais os indígenas necessitam fortalecer os seus conhecimentos. Contudo, devem incorporar novos conhecimentos para sobreviver nas sociedades, sem desvalorizar a riqueza e a importância de seus conhecimentos e tecnologias tradicionais. Ademais, sabe-se que as comunidades indígenas são cada vez mais desafiadas pelas exigências da sociedade envolvente e, de acordo com Berkes (2003, p.134), a condição para manutenção do conhecimento tradicional, a cosmovisão e as crenças "são essenciais na manutenção do equilíbrio entre estas e seu ambiente natural'.

A respeito da necessidade de incorporação de novos conhecimentos por parte dos indígenas, Toledo e Barrera-Bassols (2009, p.110) recomendam que "o conhecimento tradicional deve ser contemplado em sua íntima relação com as crenças". Com o imenso acervo de conhecimentos e tecnologias das distintas sociedades, os indígenas passaram a ser conhecidos como detentores de conhecimento específicos por possuírem modelos de manejo e gestão ambiental de ecossistemas complexos que têm perdurado por séculos, em uma prática que hoje é reconhecidamente uma manifestação do "desenvolvimento sustentável".

Pelo exposto, reforça-se o argumento de que pela etnoecologia é possível aprofundar o conhecimento sobre o modo de vida diferenciado dos indígenas, identificando as diferentes dimensões e aspectos das relações entre os índios e o ambiente natural. Muitos estudiosos e curiosos passaram a se interessar pelas culturas locais e populações tradicionais, através do estudo de seus saberes e usos do ambiente natural, seja para fins profissionais ou pela busca do exótico.

Em suma, a etnoecologia tem uma extrema relação com o desenvolvimento sustentável já que discute como associar a conservação destas áreas levando em conta as populações locais, reconhecendo que elas se relacionam com a biodiversidade e dependem dela e respeitando os saberes tradicionais e a cultura dessas comunidades (GANDOLFO et al., 2010).

\section{Resultados e discussões}

A pesquisa foi realizada na TIRSS, região Ingarikó, localizada em território que inclui o Parque Nacional Monte Roraima. A TIRSS é habitada por aproximadamente 16.484 mil índios, os quais ocupam 164 aldeias. A homologação foi caracterizada pelas reivindicações, que duraram mais de 30 anos, empreendidas pelos povos indígenas Macuxi, Wapixana, Patamona, Ingarikó, Taurepang e Sapará.

A área da Raposa Serra do Sol corresponde a 7,79\% do território de Roraima. A junção de todas as terras indígenas soma $46 \%$ do Estado; os 54\% restantes corres- 
Nogueira, E.M.N.; Ferko, G.P.S.; Costa-Neto, C.P.L.; Falcão, M.T.; Rodrigues, R.M.

pondem à soma dos estados de Alagoas, Espírito Santo e Rio de Janeiro. De acordo com Abramovay (2008, p.3), "o índice de densidade demográfica da área rural de Roraima é de 0,65 habitantes por km²', enquanto que na Raposa Serra do Sol é "1,1 $\mathrm{km}^{2}$ ". Dividindo-se "igualmente as terras do estado entre sua população rural, a terra indígena teria praticamente o dobro do tamanho que tem".

Conforme o Instituto Socioambiental - ISA (2009), a TIRSS fica a nordeste de Roraima, (Figura 1), onde vivem os Índios das etnias Macuxi, Taurepang, Patamona, Ingarikó, Wapixana e Sapará.

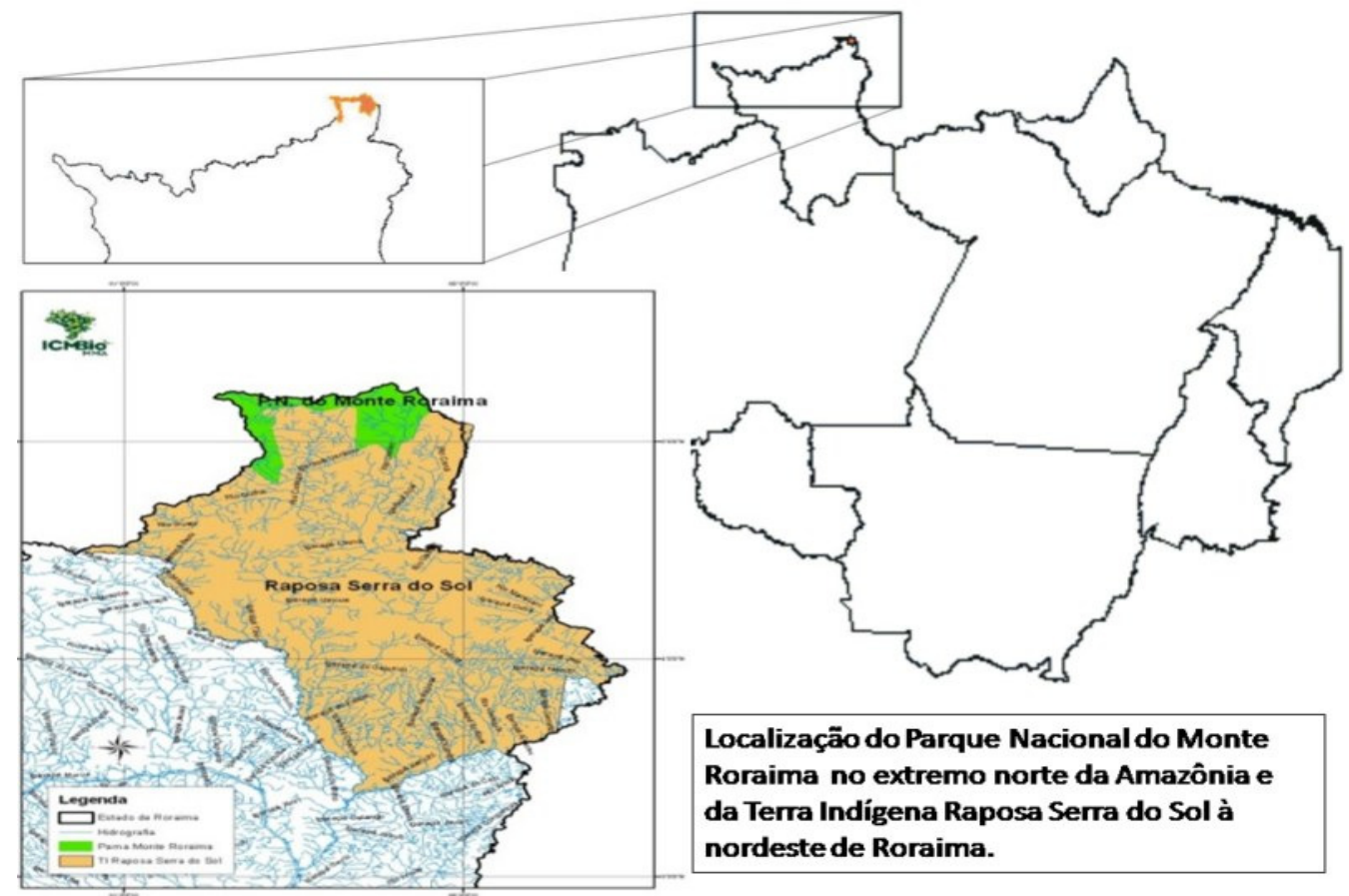

Figura 1: Localização de Roraima e do Parque Nacional no contexto da Amazônia.

Figure 1: The Roraima location and National Park in the Amazon context.

Fonte: ICMBio (2012). Source: ICMBio (2012).

Para delimitar seu território ou estabelecer limites institucionais das áreas tradicionalmente por eles ocupadas, os povos indígenas da Raposa Serra do Sol travaram uma luta que durou anos até a efetivação da demarcação dessa terra, por meio do Decreto $\mathrm{s} / \mathrm{n}$ de 15 de abril de 2005, nos termos da Portaria no 534, de 13 de abril de 2005.

Após a efetivação do processo de desintrusão dos arrozeiros da TIRSS, pouco a pouco as terras, nas mãos dos indígenas, vêm se tornando produtivas, especialmente com o aumento do rebanho de gado entre os Macuxi e Wapichana, resultado de uma iniciativa da Diocese de Roraima desde os anos de 1980, que consiste na cessão de 52 cabeças de gado a uma comunidade que, após cinco anos, deve repassar essa mesma quantidade de animais para outras aldeias (NOGUEIRA, 2013, p.89), formando uma rede de distribuição e fixação da pecuária entre os indígenas. 
Ainda conforme Nogueira (2013), a agricultura também vem ocupando espaço entre os Macuxi e Wapichana, especialmente com o aumento da produção das lavouras de mandioca, feijão, milho, além da cultura de algumas hortaliças. Essa atividade é possível graças à assistência técnica de alguns técnicos agrícolas indígenas.

Destaca-se ainda a participação de algumas comunidades no Programa de Aquisição de Alimentos - PAA - do Governo Federal, coordenado pela Secretaria de Agricultura e Abastecimento do Estado ou pela Companhia Nacional de Abastecimento CONAB. Nesse programa o excedente da produção é vendido por essas instituições ou doado a outras comunidades.

A preocupação com a possível diminuição de conhecimentos tradicionais, a maneira de transmitir os conhecimentos sobre a agricultura familiar e comunitária, sobre as plantas que curam e o cultivo de plantas frutíferas, que representam a maneira de ser dos povos e de se relacionar com a natureza e com o mundo, motivou as comunidades a questionarem-se por que não investir mais em educação, desenvolver e fazer pesquisas a respeito dos métodos de cultivos mais adequados às suas necessidades. Pensando assim:

aldeias Serra do Sol, Sauparu, Awendei, Pipi, Kumaipá, Manalai, Mapaé/ Karumanpak Tëi”, presentes na VI Assembleia Geral do Povo Ingarikó e na I Assembleia do Conselho do Povo Indígena Ingarikó (COPING), reivindicaram a criação de um centro educacional, com o propósito de trocar experiências sobre agricultura, fortalecimento da cultura, "convivência social", "práticas educativas, estudo e pesquisa, lazer e vivência comunitária do povo Ingarikó" e "dos demais povos que habitam a faixa de fronteira como os Patamona, Akawaio, Macuxi e Taurepang (OLIVEIRA, 2011, p.28).

No Plano Pata Eseru (2009), consta o fortalecimento do manejo tradicional dos indígenas como o cultivo, a moradia, a caça e o extrativismo realizado no território duplamente afetado (espaço destinado à preservação do meio ambiente e aos direitos constitucionais dos Índios). Segundo Nogueira (2013), esse documento tem como meta a identificação dos obstáculos para o desenvolvimento de atividades com baixo impacto ambiental e as potencialidades econômicas, sem modificar o modo de vida dos indígenas e com a possibilidade de melhorar as condições de vida do povo ali residente.

Recorrendo à etnoecologia, é possível aprofundar o conhecimento sobre esse modo de vida específico das comunidades indígenas, bastando para isso identificar as dimensões e aspectos das relações entre as etnias e o ambiente natural. Quanto ao modo de vida, este pode ser apreciado pelo turista.

A base da alimentação do povo Ingarikó é oriunda da mandioca, produto do qual produzem o caxiri (bebida alimentícia servida desde o café da manhã até a última refeição da noite, concentrada pela mistura cozida da mandioca e da batata) e o pajuaru (bebida produzida a partir do beiju $^{1}$ ), a damorida (cozido de peixe ou carne cujo tempero principal é a pimenta) (NOGUEIRA, 2013, p.92). 
No interior de todas as casas existe um local reservado para o preparo dos alimentos. Na hora das refeições a comida é servida sobre uma mesa ou no chão, na panela onde foi preparada, acompanhada do beiju, que é disposto sobre uma esteira de palha, um abano ou um prato ou outra vasilha; o caxiri é servido em uma tigela ou em uma jarra plástica. De acordo com Nogueira (2013), antes esse alimento era tomado na cuia ${ }^{2}$. A família faz um círculo em volta da panela e todos compartilham da alimentação, da seguinte forma: corta-se um pedaço de beiju (Figura 2), mergulha-se suavemente na damorida (Figura 3) e degusta-se sem pressa e em silêncio.
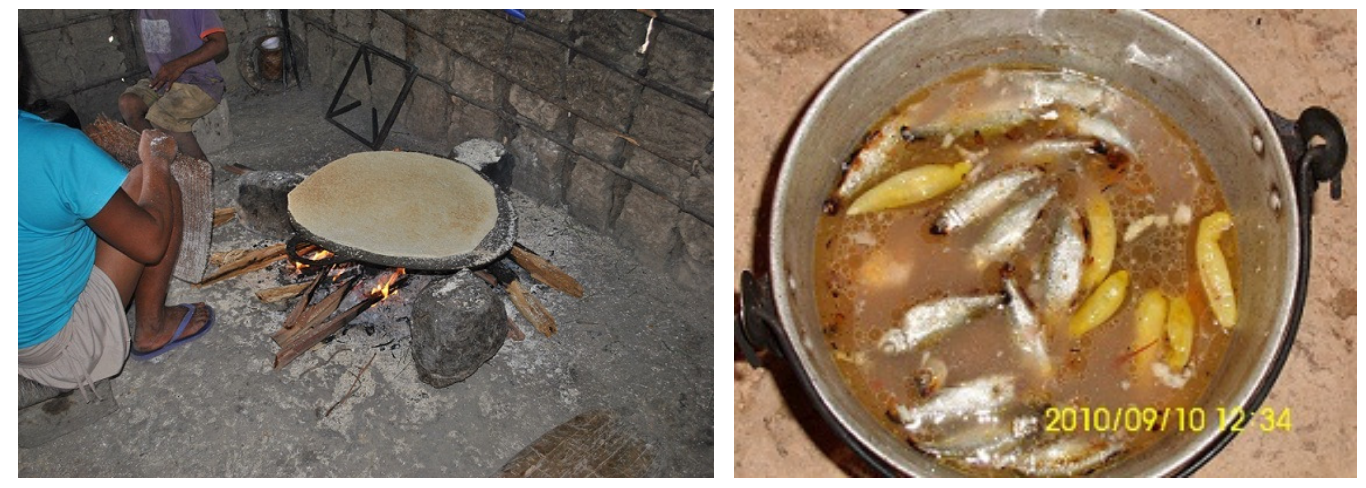

Figuras 2 e 3: Alimentação típica beiju e damorida.

Figures 2 and 3: Typical food, manioc bread and damorida.

Foto: Elizabete Melo Nogueira (2012). Photo: Elizabete Melo Nogueira (2012).

Nesse contexto, destaca-se a Igreja Coração do Mundo que faz parte da cosmovisão do povo Ingarikó e seu principal rito é a dança areruia, presente em todos os momentos da vida em comunidade. É tão forte o sentimento que uma parte da produção deve ser destinada à igreja para ser consumida coletivamente, pois acreditam que o fortalecimento da religião encorajará a comunidade na manutenção dos conhecimentos tradicionais (NOGUEIRA, 2013).

\section{Considerações finais}

Os indígenas da TIRSS são pessoas que vivem em meio aos recursos naturais e acumulam conhecimentos e saberes sobre o uso da fauna e da flora que são repassados de geração em geração. Seus costumes refletem a convivência com o ambiente natural, o que se traduz nas ricas manifestações da cultura amazônica com seus mitos, músicas, ritos, danças, artesanato e sua culinária (especialmente as produzidas a partir da mandioca). No entanto, esses conhecimentos e saberes ainda não são reconhecidos pela maioria dos membros da sociedade envolvente e, com isso, os indígenas acabam à mercê das políticas assistencialistas dos governos federal, estadual e municipal, quando poderiam estar desenvolvendo o turismo e gerando renda para a comunidade.

A aprendizagem entre os indígenas requer o fortalecimento dos saberes transmitido por via oral, especialmente aqueles relativos à relação do povo com a natureza. Por outra perspectiva, a incorporação de alguns conhecimentos da sociedade envolvente poderá ser um indutor do desenvolvimento social e econômico dessas comuni- 
dades. Sobre esse aspecto, Toledo (2008, p.20, tradução nossa) afirma que "se trata dos saberes transmitidos por via oral de geração para geração e, em especial aqueles conhecimentos imprescindíveis e cruciais, por meio dos quais a espécie humana foi moldando suas relações com a natureza".

Os povos indígenas da TIRSS têm conhecimento de sua história, do potencial de sua cultura, apresentando, dessa forma, requisitos internos para a implantação de projetos capazes de proporcionar o etnoturismo da comunidade.

Foi possível visualizar uma grande insatisfação dos indígenas com o atual cenário das aldeias. Eles reconhecem as necessidades, os problemas e as aspirações da própria comunidade.

Muitos já estão abandonando a aldeia em busca de outras formas de sustentar a família e outros deixaram de lado o fazer tradicional. Aqueles que ainda continuam apegados ao modo artesanal de produção manifestam o descontentamento com o setor público que deveria atender as necessidades, investindo em práticas que preservassem a cultura e a tradição.

O conhecimento dos indígenas precisa ser preservado e reconhecido pela sociedade, considerando-se o desenvolvimento sustentável, mesmo que em desacordo com os interesses econômicos. Como afirma Viana (2004, p.1): "isso não deverá ser resultado do altruísmo dos indígenas, extrativistas, colonos, fazendeiros e empresários [...] mas sim de políticas públicas capazes de mudar a lógica econômica da fronteira do desmatamento".

O etnoturismo pressupõe o desenvolvimento de atividades que promovam a inter-relação do homem por meio de vivências com ecossistemas, com as tradições, com os mitos locais. Para tanto, esse segmento deve ser planejado de modo que 0 turista sinta-se responsável pela conservação dos recursos e do patrimônio, via etnoecologia, e, assim, a comunidade anfitriã receberá os benefícios resultantes das atividades etnoturísticas como protagonistas do processo.

\section{Referências bibliográficas}

ABRAMOVAY, P. Terra Indígena: A guerra da raposa. Disponível em: <http:// www.diplomatique.org.br/artigo.php?id=252>. Acesso em 10 ago.2012.

AZEVEDO, L.L. Ecoturismo Indígena. Quito: Abya-Yala, 2007.

BASSI, J.B.; SOUZA, G.C.; KUBO, R.R. Etnoecologia contemporânea e interdisciplinaridade: contribuições da antropologia ecológica de Tim Ingold. Anais do IV Encontro da Rede de Estudos Rurais: Mundo rural, políticas públicas, instituições e atores em reconhecimento político. Curitiba/PR: UFPR, 2010.

BERKES, F. Toward a unity of mind and nature. In: VIEIRA, P.F. (Org.) Conservação da diversidade biológica e cultura em zonas costeiras. Florianópolis: APED, 2003. p. $115-143$. 
Nogueira, E.M.N.; Ferko, G.P.S.; Costa-Neto, C.P.L.; Falcão, M.T.; Rodrigues, R.M.

BRASIL. Turismo Cultural: orientações básicas. Marcos Conceituais do Mtur. Ministério do Turismo, Secretaria Nacional de Políticas de Turismo. Departamento de Estruturação, Articulação e Ordenamento Turístico, Coordenação-Geral de Segmentação. - 3. ed.- Brasília: Ministério do Turismo, 2010. 96p.

BRASIL. Segmentação do Turismo. Conceitos. Documento preliminar, não revisado. Brasília: Ministério do Turismo, 2005.

BRITO T.M. Turismo e Povos Indígenas. Anuário de Produção Acadêmica Docente. Vol III, N4, ano 2009. Anhanguera Educacional S.A. Publicação 19 de março de 2010.

CAMPOS, M.D. Etnociência ou etnografia de sabers, técnicas e praticas? In: AMOROSO, M.C.; MING, L.C.; SILVA, S.M.P. (orgs.) Métodos de coleta e análise de dados em etnobiologia, etnoecologia e disciplinas correlatadas. Rio Claro, UNESP/CNPQ, 2002.

CAMPOS, A.M.N. O ecoturismo como alternativa de desenvolvimento sustentável. Revista Turismo, 2005, Disponível: <www. revistaturismo.com.br/artigo/eco-desenvsut.htm> . Acesso: 13 ago. 2005.

CHERNELA, J.M. Povos Indígenas e Turismo Cultural: Condições para sustentabilidade. In: NELSON. S.P.; PEREIRA, E.M. (Orgs). Ecoturismo: Práticas para turismo Sustentável. Manaus: Editora Vale/Uninorte, 2004.

COSTABEBER, J.A.; CAPORAL, F.R. Possibilidades e alternativas do desenvolvimento rural sustentável. In: VELA, H. (Org.). Agricultura Familiar e Desenvolvimento Rural Sustentável no Mercosul. Santa Maria: Editora da UFSM/Pallotti, 2003. p. 157-194.

DALE, P. Definindo ecoturismo... Para quê? Para quem? In: MENDONÇA, R.; NEIMA, Z. (Orgs). Ecoturismo no Brasil. São Paulo: Manole, 2005.

DALY, H.E. Crescimento sustentável? Não obrigado. Ambiente \& Sociedade, vol. VII no 2, São Paulo, jul/Dez 2004.

DIEGUES, A.C. O mito moderno da natureza intocada. São Paulo: NUPAUB - Núcleo de Apoio à Pesquisa sobre Populações Humanas e Áreas Úmidas Brasileiras - USP: 2005.

ESTENDER, A.C.; PITTA, T.T.M. O conceito do desenvolvimento sustentável. 2007, disponível: <www.institutosiegen.com.br/ artigos/conceito_desenv_sustent.pdf>. Acesso: 19 ago. 2012. 14 p.

ESTENDER, A.C.; PITTA, T.T.M. Ecoturismo Indígena: Território, Sustentabilidade, Multiculturalismo. São Paulo: Annablume, 2012.

FERNANDEZ, B.P.M. Ecodesenvolvimento, Desenvolvimento Sustentável e Economia Ecológica: em que sentido representam alternativas ao paradigma de desenvolvimento tradicional? Revista Desenvolvimento e Meio Ambiente, № 23, p. 109-120, Paraná: Editora UFPR, jan/jun. 2011.

GANDOLFO, E.S. et. al. A etnoecologia como zona de convergência entre ensino, pesquisa e extensão. In: GUIMARÃES, L.B.; KRELLING, A.G.; BARCELOS, V. Tecendo educação ambiental na arena cultural. Trabalhos do Grupo Tecendo: Educação Ambiental e Estudos Culturais da UFSC, Petrópolis, RJ: DP et Alli, 2010, p. 139-158. 
HANAZAKI, N. Etnoecologia, Etnobiologia e as interfaces entre o conhecimento científico e o conhecimento local. Anais/ Resumos, 58 ${ }^{\text {a }}$ reunião SBPC, Santa Catarina: UFSC, 16 a 21 de julho de 2006. Disponível: <http://www.sbpcnet.org.br /livro/58ra/atividades/ TEXTOS/texto_290.html>. Acesso: 17 abr. 2012.

INSTITUTO SOCIOAMBIENTAL. Entenda o que está acontecendo na Terra Indígena Raposa-Serra do Sol, em Roraima. Disponível em: <http://www.socioambiental.org/nsa/ detalhe?id=1526>. Acesso: 18 jun. 2009.

LEAL, R.E.S. O turismo desenvolvido em territórios indígenas sob o ponto de vista antropológico. In: BARTHOLO, R.; SANSOLO, D.G.; BURSZTYN, I. (org). Turismo de base comunitária: diversidade de olhares e experiências brasileiras. Rio de Janeiro: Letra e Imagem, 2009.

LITTLE, P.E. Etnoecologia e direitos dos povos: elementos de uma nova ação indigenista. In. SOUZA LIMA, A.C.; BARROSO-HOFFMANN, M. (org.). Etnodesenvolvimento e politicas públicas. Rio de Janeiro, LACED, Contracapa, 2002.

MARQUES, J.G.W. O olhar (Des)multiplicado. O papel interdisciplinar e do qualitativo na pesquisa etnobiológica e etnoecológica. In: AMOROZO, M.C.M.; MING, L; SILVA, S.P. Métodos de coleta e análise de dados em Etnobiologia, Etnoecologia e Disciplinas Correlatas. Rio Claro: Anais do I Seminário de Etnobiologia e Etnoecologia do Sudeste, Coordenadoria da área de Ciências Biológicas, UNESP/CNPQ, 2001. 204 p.

MARQUES, P.C.L. Turismo Alternativo no Pátio de São Pedro: Estabelecimento de Relações entre Turistas e Manifestações Culturais Pernambucanas. In: BAHL, M., MARTINS, R.C.R.; MARTINS, S.F. O Turismo como força transformadora do Mundo Contemporâneo. São Paulo: ROCA, 2005, 105 - 113.

MIECZKOWSKI, Z. Environmental issues of tourism and recreation. University Press of America, Inc: Lantarn, Maryland, 1995.

MUÑOZ, M.G. Saber Indígena e Meio Ambiente: Experiência de Aprendizagem Comunitária. In: LEFF, E. (Coord). A Complexidade Ambiental. São Paulo: Cortez, 2003.

NAZAREA, V.D. Introduction: a view from a point: Ethnoecology as situated knowledge. In: NAZAREA, V.D. (ed.). Ethnoecology: Situated knowledge/located lives. The University of Arizona Press, Arizona, USA: 1999, p. 3-20.

NEIMAN, Z.; MENDONÇA, R. (org). Ecoturismo no Brasil. Barueri, São Paulo: Manole, 2005.

NOGUEIRA, E.M.; GHEDIN, L.M. A Pesca Esportiva como suporte para o turismo de base local no baixo Rio Branco no Estado de Roraima. Anais: XI Encontro Nacional de Turismo com Base Local - ENTBL, Niterói: 2010. pp. 781 - 896, ISSN 1808-9755.

NOGUEIRA, E.M. Etnodesenvolvimento e Educação Indígena: Problemas e perspectivas para a implantação do Etnoturismo na Terra Indígena Raposa Serra do Sol (TIRSS), Região Ingarikó - Wîl TÎPÎ. Dissertação de Mestrado. Programa de Pós-Graduação em Educação Agrícola - PPGEA, Rio de Janeiro: UFRRJ, 2013. 152p.

NORDI, N. et. al. Etnoecologia, Educação Ambiental e Desenvolvimento Sustentável. In: SANTOS, J.E.; SATO, M. A contribuição da educação ambiental à esperança de pandora. São Carlos: Rima, 2001, 2003. p.133-144. 
Nogueira, E.M.N.; Ferko, G.P.S.; Costa-Neto, C.P.L.; Falcão, M.T.; Rodrigues, R.M.

OLIVEIRA, S.L. (Cons.). Projeto de cooperação técnica internacional BRA/ IICA/07/009 - desenvolvimento territorial. Relatório Contendo Análise e parecer sobre os projetos de infraestrutura propostos em 2011 no Território Terra Indígena Raposa Serra do Sol. Boa Vista: IICA, SDT, MDA, 2011.

OLIVEIRA, S.L. Relatório contendo análise e parecer sobre os projetos de infraestrutura propostos em 2011 no Território Terra Indígena Raposa Serra do Sol. Boa Vista Roraima: IICA-OEA/Secretaria de Desenvolvimento Territorial/Ministério do Desenvolvimento Agrário, Junho de 2011.

OMT. Introducción al Turismo. Madrid: OMT, 2002.

REYES-GARCÍA, V., SANZ, N.M. Etnoecología: punto de encuentro entre naturaleza y cultura. Ecosistemas - Revista Científica y Técnica de Ecología y Medio Ambiente, 16 (3), septiembre, 2007, Disponible: <http://www.revista ecosistemas.net/articulo.asp? ld $=501>$. Acceso en 20 nov.2012. p. 46-55.

RUSCHMANN, D.V.M. Turismo e planejamento sustentável: a proteção do meio ambiente. Campinas, SP: Papirus, 2008.

SACHS, I. Estratégias de transição para o século XXI. In: BURSZTYN, M. Pensar o Desenvolvimento Sustentável. São Paulo: IBAMA/ENAP, primeira edição, 1993.

SILVA, J.G. Além da RIO + 20: Juntos por um futuro sustentável. Revista Eco-21, Rio de Janeiro: PUC-RIO, ed. 188, 2012.

SOUZA, G.C. de et al. Etnobiologia, multidisciplinaridade e extensão: conflitos de uso dos recursos naturais e a etnoconservação. In: ARAÚJO, T.A.S.; ALBUQUERQUE, U.P. Encontros e desencontros na pesquisa etnobiológica e etnoecológica: os desafios do trabalho em campo, Recife: NUPEEA, 2009. 288 p.

TOLEDO, V. M. What is ethnoecology? Origins, scope and implications of a rising discipline. Etnoecológica, 1992.

TOLEDO, V. M.; Víctor M.; BARRERA-BASSOLS, N. La memoria biocultural la importancia Ecológica de las sabidurías tradicionales perspectivas agroecológicas. Junta de Andalucia - Consejería de agricultura y pesca, Barcelona: Icaria editorial, Perspectivas agroecológicas, 2008.

TOLEDO, V. M., BARRERA-BASSOLS, N. A etnoecologia: uma ciência pós-normal que estuda as sabedorias tradicionais. Desenvolvimento e Meio Ambiente, n. 20, Paraná: editora UFPR, jul/dez, 2009 - p. 31-45.

VIANA, V.M. Desenvolvimento sustentável e áreas protegidas na Amazônia. Revista Eco 21, Ano XIV, edição 86, Rio de Janeiro, 2004. p. 1 -5.

WCED. Our common Future. Oxford: Oxford University Press, 1991.

WEARING, S.; NEIL, J. Ecoturismo-Impacto, Tendencias y Posibilidades, Madrid: Editorial Síntesis, 2001.

WTTC. Investigación de Impacto Económico. Disponível: <http://www.wttc.org/ research/economic-impact-research/>. Acesso: 23 ago. 2012. 


\section{Notas:}

${ }^{1}$ Alimento feito da massa da mandioca semelhante a uma bolacha de tamanho maior.

2 Tigela feita da casca da cuieira para tomar caxiri ou comer outro alimento.

Elizabete Melo Nogueira: Instituto Federal de Educação, Ciência e Tecnologia de Roraima, Boa Vista, RR, Brasil.

Email: betemnogueira@gmail.com

Link para o currículo Lattes: http://lattes.cnpq.br/7571793745280814

Georgia Patrícia da Silva Ferko: Universidade Federal de Roraima, Boa Vista, RR, Brasil. Email: geoufpe@yahoo.com.br

Link para o currículo Lattes: http://lattes.cnpq.br/8762583706265854

Canrobert Penn Lopes Costa Neto: Universidade Federal Rural do Rio de Janeiro, Rio de Janeiro, RJ, Brasil.

Email: canrobertp@uol.com.br

Link para o currículo Lattes: http://lattes.cnpq.br/4801851220092783

Raimunda Maria Rodrigues Santos: Instituto Federal de Educação, Ciência e Tecnologia de Roraima, Boa Vista, RR, Brasil.

Email: raimundarodrigues@ifrr.edu.br

Link para o currículo Lattes: http://lattes.cnpq.br/7428971100040320

Márcia Teixeira Falcão : Universidade Estadual de Roraima, Boa Vista, RR, Brasil.

Email: marciatfalcao@oi.com.br

Link para o currículo Lattes: http://lattes.cnpq.br/1671906250858943

Data de submissão: 30 de junho de 2013

Data de recebimento de correções: 30 de junho de 2013

Data do aceite: 01 de setembro de 2013

Avaliado anonimamente 